\title{
Self-assembled gold nanoparticles and amphiphile peptides: a colorimetric probe for copper(ii) ion detection
}

Article

Accepted Version

Pelin, J. N. B. D., Edwards-Gayle, C. J. C., Martinho, H., Gerbelli, B. B., Castelletto, V., Hamley, I. W. and Alves, W. A. (2020) Self-assembled gold nanoparticles and amphiphile peptides: a colorimetric probe for copper(ii) ion detection. Dalton Transactions, 45. pp. 16226-16237. ISSN 1364-5447 doi: https://doi.org/10.1039/D0DT00844C Available at https://centaur.reading.ac.uk/90615/

It is advisable to refer to the publisher's version if you intend to cite from the work. See Guidance on citing.

To link to this article DOI: http://dx.doi.org/10.1039/D0DT00844C

Publisher: Royal Society of Chemistry

All outputs in CentAUR are protected by Intellectual Property Rights law, including copyright law. Copyright and IPR is retained by the creators or other copyright holders. Terms and conditions for use of this material are defined in the End User Agreement. 


\section{CentAUR}

Central Archive at the University of Reading

Reading's research outputs online 
Self-assembled Gold Nanoparticles and Amphiphile Peptides: A Colorimetric Probe for Copper(II) Ion Detection

Juliane N. B. D. Pelin,,${ }^{[a, b]}$ Charlotte J. C. Edwards-Gayle, ${ }^{[b]}$ Herculano Martinho, ${ }^{[a]}$ Bárbara

B. Gerbelli, ${ }^{[a]}$ Valeria Castelletto, ${ }^{[\mathrm{b}]}$ Ian W. Hamley, ${ }^{[\mathrm{b}]}$ Wendel A. Alves ${ }^{[\mathrm{a}], *}$

${ }^{[a]}$ Centro de Ciências Naturais e Humanas, Universidade Federal do ABC, 09210-580, Santo André, Brazil

${ }^{[b]}$ Department of Chemistry, University of Reading, Reading RG6 6AD, United Kingdom

Corresponding Author

*E-mail: wendel.alves@ufabc.edu.br 


\begin{abstract}
Morphological, spectroscopic and scattering studies of the self-assembly and aggregation process of hybrids containing gold nanoparticles (AuNPs) and the amyloid peptides $[\mathrm{RF}]_{4}$ and $\mathrm{P}[\mathrm{RF}]_{4}$ (where $\mathrm{R}=$ arginine; $\mathrm{F}=$ phenylalanine; $\mathrm{P}=$ proline) in aqueous solution were performed. Two methodologies were tested for the AuNP nucleation, using sodium borohydride $\left(\mathrm{NaBH}_{4}\right)$ or epigallocatechin gallate (EGCG) as a reducing agent. This led to remarkable distinct modes of assembly, AuNP decorated fibrils with $\mathrm{NaBH}_{4}$ reduction or isolated AuNPs with EGCG reduction. For both methodologies, the presence of spherical AuNPs was observed by plasmonic resonance bands in absorption spectra at $520 \mathrm{~nm}$. Zeta potential measurements confirmed stable systems, with a similar aggregation state. Circular dichroism spectra revealed an antiparallel $\beta$-sheet conformation of the peptides. The transmission electron microscopy (TEM) images showed the coexistence of nanometer fibers and globular nanoparticles with $20 \mathrm{~nm}$ size. The small-angle X-ray scattering (SAXS) results show that the $\mathrm{NaBH}_{4}$ systems presented large cylindrical structures, while with increasing $\mathrm{P}[\mathrm{RF}]_{4}$ content, a decrease in radius was observed. However, the EGCG-AuNPs were characterized by spherical particles, with a radius of 10 $-20 \mathrm{~nm}$. Also, the colorimetric efficiency of the hybrids in the capture of $\mathrm{Cu}^{2+}$ ions in solution was monitored. Raman spectroscopy data confirmed the conformational/structural of self-assembled samples. Moreover, there is indications for surface-enhanced Raman spectroscopy (SERS) effect for $\mathrm{Cu}^{2+}$ sites. The set of results indicates that these systems could act as a promising sensitive metal concentration probes.
\end{abstract}




\section{INTRODUCTION}

Green chemistry has gained increasing prominence in recent decades due to environmental concerns and desire to increase process efficiency. Over the last 20 years, self-assembled systems based on peptides have attracted strong interest due to their enormous potential for bionanotechnological applications. Among several promising uses, we can highlight the development of sensing devices, molecular carriers, bioelectronics, tissue engineering, and so on. Many advantages - especially the fast synthesis, functionalization capabilities, and relatively low cost - confirm the potential of these systems. ${ }^{[1-7]}$ The detailed knowledge about the structure of these systems and its influence on the resulting chemical and physical properties is a crucial step for understanding these materials and designing new applications.

Among the molecular groups able to form self-assembled structures, amphiphiles have a prominent position. They can self-assemble into polymorphs with a large variety of liquid-crystalline phases. In this way, these systems are appropriate architectures to formulate biomimetic materials and establish interfaces with biological systems. Furthermore, they are excellent physical models for investigating fundamental processes in soft materials. When amphiphilic entities are conjugated to amino acids, these hybrid systems can take advantage of chemical diversity and molecular recognition properties offered by these building blocks and substantially increase their range of application.

Various molecules can be attached to peptides to affect their self-assembly properties and direct their assembly into particular desired structures. The inclusion of specific peptide sequences with unique biological features has resulted in a large number of biocompatible biomaterials, being self-assembled by using peptide conjugates as building blocks. ${ }^{[8-10]}$ For example, we investigated the effect of oligopeptides comprising alternating $L$-arginine $(\mathrm{R})$ and $L$-phenylalanine $(\mathrm{F})$ sequences, which show an increase in their organization levels with the increase in the number of repeats, ${ }^{[11-13]}$ and these architectures can influence the morphology of the particles, since nanospherical aggregates or nanofibers are observed, depending on the peptide concentration and the $\mathrm{pH}$ of the medium. ${ }^{[14]}$

Another factor to be considered is the influence of the reducing agent on the stability process of gold nanoparticles in solution. The gold reduction depends on the strength of these reagents, by which the nanoparticle morphology and size can be changed and, consequently, their physical-chemical properties. One of the most widely used reducing agents for the AuNP synthesis is the $\mathrm{NaBH}_{4}$, characterized by a strong ability to reduce 
$\mathrm{Au}^{3+}$ to $\mathrm{Au}$ in seconds, controlling the size of the particles at the nanoscale. ${ }^{[15]}$ Recently some works used EGCG [epigallocatechin gallate] to produce regular AuNPs ( $<50 \mathrm{~nm}$ ); it is an active polyphenol flavonoid present in green tea and shows great potential in nanomedicine, acting as anti-inflammatory, anti-cancer, and anti-obesity. ${ }^{[16-19]}$

With increasing industrialization, heavy metal pollution has become more problematic, and consequently, severe damage in the environment is observed. Contamination by these materials is straightforward, but their elimination is quite difficult in biological material recycling and energy exchange. ${ }^{[20]}$ Many strategies to capture metal ions were developed in the last years, however specifically for systems containing gold nanoparticles, the colorimetric detection is gaining interest due to the capability of multi-ion sensitivity ${ }^{\text {[21-29] }}$ and detecting interactions between amino acids or peptides and metal ions. ${ }^{[22,30-32]}$ Here we explored the self-assembly process of $[R F]_{4}$ and $\mathrm{P}[\mathrm{RF}]_{4}$ peptides conjugates with AuNPs in water solution, evaluating changes in the properties of these hybrids by varying the reducing agent $\left(\mathrm{NaBH}_{4}\right.$ and $\left.\mathrm{EGCG}\right)$ and we demonstrate the efficiency of these hybrids in the detection of $\mathrm{Cu}^{2+}$ ions, which is present in water, food, air, and biological systems. ${ }^{[20]}$

\section{EXPERIMENTAL METHODS}

\subsection{Synthesis of oligopeptides peptides}

Peptides with $[\mathrm{RF}]_{4}$ and $\mathrm{P}[\mathrm{RF}]_{4}$ sequences were synthesized using a solid phase Fmoc strategy. ${ }^{[33]}$ All chemicals were of analytical or HPLC grades. The protected amino acids, (Fmoc-F-OH), (Fmoc-R(Pbf)-OH) and (Fmoc-P-OH), 1,3-diisopropylcarbodiimide/Nhydroxybenzotriazole (DIC/HOBt), trifluoroacetic acid (TFA), anisole, thioanisole, dichloromethane (DCM), dimethylformamide (DMF), 1-methyl-2-pyrrolidinone (NMP) and 1,2-ethanedithiol (EDT) were purchased from Sigma-Aldrich (Saint Louis, MO). Wang resin with 100-200 mesh size was purchased from Advanced Chemtech (Louisville, $\mathrm{KY}$ ), with a substitution degree of $0.55 \mathrm{mmol} \mathrm{g}^{-1}$ and first amino acid coupled to the polymeric support. The protected group was removed by reaction with $20 \%$ of 4 methylpiperidine in dimethylformamide for $30 \mathrm{~min}$. Coupling was carried out in a 5.0 fold excess of DIC/HOBt in DCM/DMF $(1: 1, v: v)$. The reactions were monitored using the Kaiser ninhydrin test. ${ }^{[34]}$ The dry protected resin was exposed to $90 \%$ trifluoroacetic acid, $5.0 \%$ thioanisole, $3.0 \%$ 1,2-ethanedithiol, and $2.0 \%$ anisole to remove all the protecting groups. After this, the material was lyophilized and analyzed on a liquid-chromatography electrospray ionization mass spectrometer, LC-ESI-MS, yielding $[R F]_{4}(\mathrm{MM}+\mathrm{H})=$ 
$1232.6 \mathrm{~g} \mathrm{~mol}^{-1}\left(\right.$ calculated $\left.=1231.6 \mathrm{~g} \mathrm{~mol}^{-1}\right)$ and $\mathrm{P}[\mathrm{RF}]_{4}(\mathrm{MM}+\mathrm{H})=1328.7 \mathrm{~g} \mathrm{~mol}^{-1}$ (calculated $\left.=1327.7 \mathrm{~g} \mathrm{~mol}^{-1}\right){ }^{[14]}$

\subsection{Functionalization of the AuNPs with $[R F]_{4}$ and P $[R F]_{4}$}

The solutions of AuNPs were prepared using $0.5 \mathrm{wt} \% \mathrm{HAuCl}_{4}$ and two reducing agents were tested: $0.3 \mathrm{wt} \%$ sodium borohydride $\left(\mathrm{NaBH}_{4}\right)$ or $0.5 \mathrm{wt} \%$ epigallocatechin gallate (EGCG) in the presence of the peptides $(0.5 \mathrm{wt} \%)$. The solutions were adjusted to $\mathrm{pH} 4$ after the addition of the reducing agent, using a $0.1 \mathrm{~mol} \mathrm{~L}^{-1} \mathrm{HCl}$.

Two series of experiments were evaluated in this work: the effect of peptide concentration changes, fixing the $\mathrm{HAuCl}_{4}$ concentration in $0.5 \mathrm{wt} \%$, and the influence on the self-assembly process of peptide mixtures. In the first case, systems with different proportions of $\mathrm{HAuCl}_{4} /$ peptide ratios were studied, considering the proportions 6.7, 3.3, and 2.3 for $\mathrm{HAuCl}_{4} /[\mathrm{RF}]_{4}$, and 5.0, 2.5, 1.7 for $\mathrm{HAuCl}_{4} / \mathrm{P}[\mathrm{RF}]_{4}$, using $\mathrm{NaBH}_{4}$.

For the mixtures of $\mathrm{P}[\mathrm{RF}]_{4} /[\mathrm{RF}]_{4}$ different proportions were selected in the following proportions $(v / v)$ : 0:1 (1), 3:7 (2); 5:5 (3), 7:3 (4) and 1:0 (5) of P[RF $]_{4} /[R F]_{4}$ with AuNPs nucleated with $\mathrm{NaBH}_{4}$ and 0:1 (6), 3:7 (7); 5:5 (8), 7:3 (9) and 1:0 (10) of P[RF $]_{4} /[\mathrm{RF}]_{4}$ with AuNPs nucleated with EGCG.

All reagents used had analytical purity: $\mathrm{HAuCl}_{4}$ (tetrachloroauric acid(III)) - Sigma Aldrich; $\mathrm{NaBH}_{4}$ - Sigma Aldrich; EGCG - Sigma Aldrich; $\mathrm{NaOH}$ (sodium hydroxide) Synth; $\mathrm{HCl}$ (hydrochloric acid. All solutions were prepared with water purified by the Direct-Q System, Millipore, with a resistivity of $18.2 \mathrm{~m} \Omega \mathrm{cm}^{-1}$ (at $25^{\circ} \mathrm{C}$ ) and TOC below $10 \mathrm{ppb}$.

\subsection{Spectroscopy methods}

Absorbance profiles were monitored over a range of 200 to $800 \mathrm{~nm}$ on a Varian Cary 50 Bio UV/Vis spectrophotometer, using quartz cuvettes with $1.0 \mathrm{~cm}$ path length. The baseline was corrected using a water buffer solution running under the same conditions (blank) and was subtracted from the experimental spectra.

Zeta potential measurements were made on a Zetasizer Nano ZS instrument (Malvern) using disposable folded capillary cells (DTS1060).

For the evaluation of the secondary structure of the samples, circular dichroism (CD) spectra were carried out using a Jasco-815 CD spectropolarimeter (Jasco Co) or a Chirascan spectropolarimeter (Applied Photophysics, UK). The samples were scanned at $25{ }^{\circ} \mathrm{C}$ in a quartz cuvette with a thickness of $0.01 \mathrm{~mm}$. The spectra were recorded with 
absorbance $\mathrm{A}<2$ at any measured point, considering $0.5 \mathrm{~nm}$ step, $1 \mathrm{~nm}$ bandwidth, and 1 s collection time per step. A water background CD signal was used to subtract the baseline from the experimental data.

Dispersive Raman spectra were performed using a Horiba Jobin Yvon T64000 Triple Spectrometer. $2 \mu \mathrm{L}$ of the sample was deposited on a silicon plate and, after being dried at room temperature, was excited with a $532 \mathrm{~nm}$ laser (Verdi G5, Coherent Inc. USA), $1 \mathrm{~mW}$, focused on a $0.5 \mu \mathrm{m}$ radius spot (50x objective). The acquisition time was 30 seconds.

\subsection{Small-Angle X-ray Scattering and Small-Angle Neutron Scattering}

Small-Angle X-Ray Scattering (SAXS) was performed on beamline B21, Diamond Light Source, Didcot, UK. A EMBL BioSAXS robot containing a 96 well plate was used, where 100 $\mu \mathrm{L}$ of the $0.5 \mathrm{wt} \%$ peptide solutions were injected via an automated sample exchanger into a quartz capillary, with $1.8 \mathrm{~mm}$ internal diameter, in a vacuum chamber. The SAXS beamline operated with a fixed camera length and energy of $3.9 \mathrm{~m}$ and $12.4 \mathrm{keV}$, respectively, and the SAXS pattern was recorded using a PILATUS 2M detector. Data processing was performed using ScÅtter on the beamline, and fitting was performed using SASfit. ${ }^{[35]}$

Small-Angle Neutron Scattering (SANS) data measurements were performed on beamline Larmor at ISIS Neutron and Muon Source, Didcot, UK. Quartz cuvettes with a thickness of $0.01 \mathrm{~mm}$ were filled with $500 \mu \mathrm{L}$ of the $0.5 \mathrm{wt} \%$ hybrid solutions, synthesized with $\mathrm{NaBH}_{4}$, and prepared using a solvent mixture of $30 \% \mathrm{D}_{2} \mathrm{O}: 70 \% \mathrm{H}_{2} \mathrm{O}$. An incident beam with a wavelength range of $1.7 \AA$ to $10 \AA$ and momentum transfer of $0.003 \AA$ to 1.0 $\AA ̊$ was used. Data processing was performed using MANTID, and fitting was performed using SASfit. ${ }^{[35]}$

\subsection{TEM imaging}

Transmission electron microscopy (TEM) experiments were carried out at the Brazilian Nanotechnology National Laboratory (Campinas, Brazil) on a JEOL model JEM-2100 instrument, operating at $200 \mathrm{kV}$, and at the University of Reading, on a JEOL 2100Plus, instrument operating at $200 \mathrm{kV}$. Copper grids (Agar Scientific, UK) $5.0 \mathrm{~mm}$ in diameter and $10 \mu \mathrm{m}$ thick, coated with carbon film, were used.

\subsection{Detection of $\mathrm{Cu}^{2+}$ using the peptide-AuNPs systems by colorimetric assays}

Solutions containing $80 \mu \mathrm{L}$ of $\left(\mathbf{1}, \mathbf{3}, \mathbf{5}, \mathbf{6}, \mathbf{8}\right.$, and 10) hybrids and $300 \mu \mathrm{L}$ of $\mathrm{CuCl}_{2}(7.0$ to $223 \mu \mathrm{mol} \cdot \mathrm{L}^{-1}$ ), purchased from Sigma Aldrich, were analyzed in UV/Visible absorbance spectroscopy. The experiments were made in triplicate. 


\section{RESULTS}

\subsection{Nucleation of AuNPs in $[R F]_{4}$ and $P[R F]_{4}$ systems}

These hybrids containing amyloid peptides and AuNPs were stabilized in water solutions at $\mathrm{pH} 4$ since zeta-potential assays indicate an isoelectric point for both peptides. ${ }^{[14]}$ An important characteristic of metallic nanoparticles is the presence of the plasmon resonance bands, which can be analyzed in a qualitative way to describe the form and size of the particles. ${ }^{[36]}$ Figure 1a shows the spectrum for the $[R F]_{4}$ hybrids. In this case, a small band at approximately $258 \mathrm{~nm}$ was observed, characteristic of the amino acid phenylalanine ${ }^{[37]}$ and a band of higher intensity at $530 \mathrm{~nm}$, which is related to the spherical gold nanoparticles. ${ }^{[36,38]}$ We also observed that even with the increase in peptide concentration, the intensity and width of the bands remained the same, i.e., these phenomena indicate a homogeneity of the particles formed in the aggregation process.

Considering the hybrids of $\mathrm{P}[\mathrm{RF}]_{4}$, the spectra in Figure $1 \mathrm{~b}$ show the characteristic band of phenylalanine at $\sim 258 \mathrm{~nm},{ }^{[37]}$ however, with a much smaller and broader intensity, which suggests the formation of larger aggregates. For the plasmon resonance band of gold, displacement of its maxima was observed, varying between $520 \mathrm{~nm}$ and $550 \mathrm{~nm}$, with the increase of the concentration of the $\mathrm{P}[\mathrm{RF}]_{4}$. Despite having a globular characteristic, ${ }^{[36,38]}$ these nanoparticles are larger as the ratio of the hybrid ( $\mathrm{HAuCl}_{4} /$ peptides) decreases, indicating differences in the morphology of these self-assembled materials.

For the hybrids containing the mixtures of $\mathrm{P}[\mathrm{RF}]_{4}$ and $[\mathrm{RF}]_{4}$, the phenylalanine band is observed at $\sim 258 \mathrm{~nm} .{ }^{[37]}$ The samples prepared with $\mathrm{NaBH}_{4}$ are characterized by a band at $546 \mathrm{~nm}$, which for sample (1) showed the lowest intensity, while (3) and (4) presented the highest intensity, as can be seen in Figure 1c. Considering the EGCG systems, a band located at $567 \mathrm{~nm}$ (Figure 1d) was observed for all proportions, suggesting the formation of bigger aggregates in comparison with the $\mathrm{NaBH}_{4}$ hybrids. Also, a gradual enhancement of the intensity is verified, increasing the $\mathrm{P}[\mathrm{RF}]_{4}$ content, which can be correlated with a higher amount of globular gold nanoparticles in the solutions.

Systems containing only AuNPs synthesized using both reducing agents also showed a band at $560 \mathrm{~nm}$ and $568 \mathrm{~nm}$, respectively, for $\mathrm{NaBH}_{4}$ and EGCG, indicating spherical structures. As observed for the samples with the peptides, EGCG systems tend to form bigger particles in comparison with the $\mathrm{NaBH}_{4}$, and this is characterized in Figure 1d by the enlargement and shifting of the plasmonic band. 

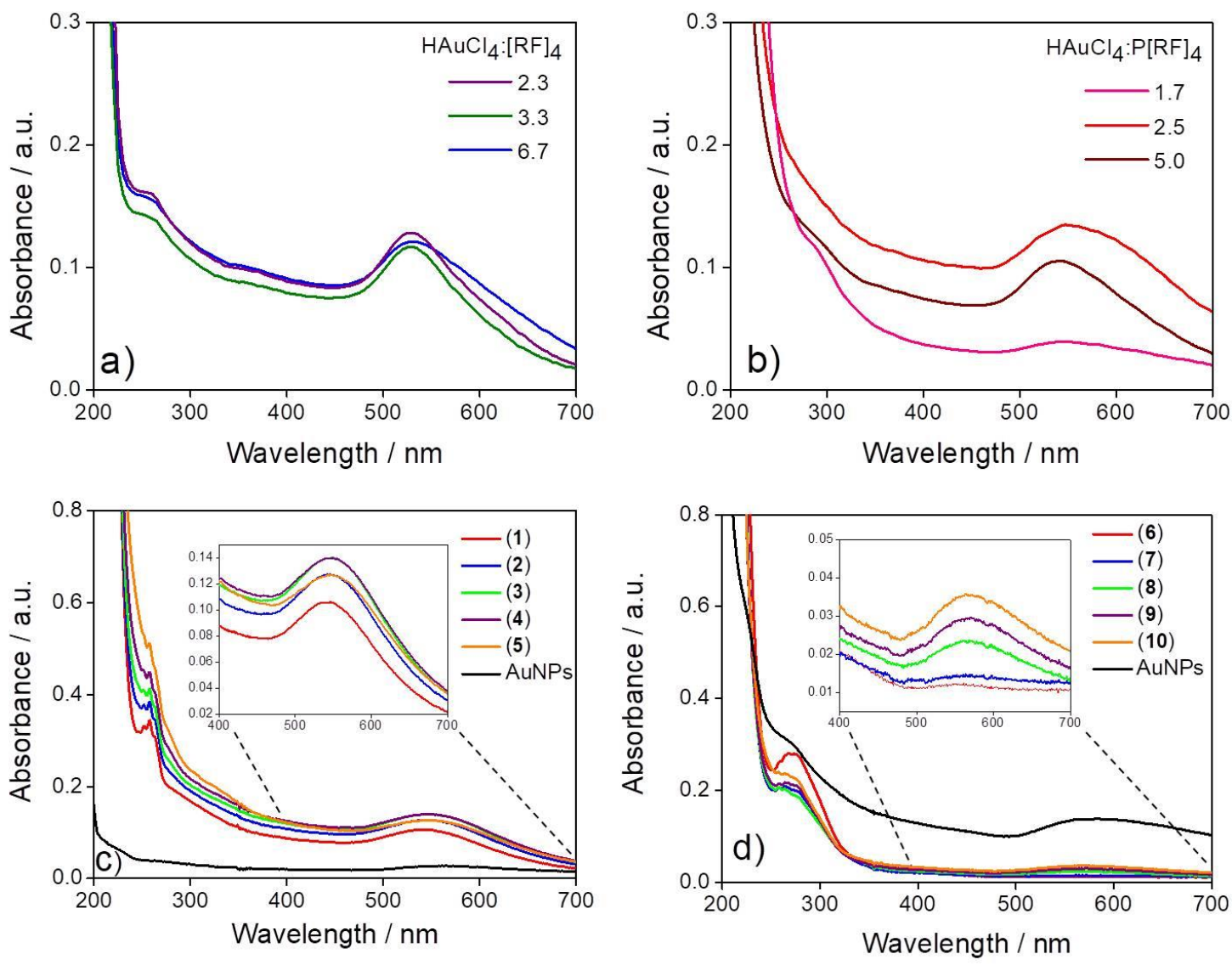

Figure 1. UV/Vis absorption spectra for samples with different proportions of a) $\mathrm{HAuCl}_{4} /[\mathrm{RF}]_{4}$ and b) $\mathrm{HAuCl}_{4} / \mathrm{P}[\mathrm{RF}]_{4}$, both synthesized using $\mathrm{NaBH}_{4}$. The same measurements were performed using different mixtures of $\mathrm{P}[\mathrm{RF}]_{4} /[\mathrm{RF}]_{4}$ in c) $\mathrm{HAuCl}_{4}-\mathrm{NaBH}_{4}$ and d) $\mathrm{HAuCl}_{4}$-EGCG.

Zeta potential measurements of the $\mathrm{HAuCl}_{4} /$ peptide solutions prepared with $\mathrm{NaBH}_{4}$ were made to probe the stability of the aggregates, considering the surface charge in regard to the aggregation tendency and its possible redispersibility. ${ }^{[39]} \mathrm{At} \mathrm{pH} 4$, the solutions had positive zeta potentials with similar values, indicating that they may have identical aggregation states. The summarized data is presented in Table S1. As verified before by UV/Vis absorption spectroscopy, the systems are stable, suggesting that the organization of the monomers present is the same, and the proline residue does not influence the selfassembly process. DLS assays were performed (Figures S1 and S2), and the results corroborate with the other spectroscopic techniques, proving the systems have similar selfassembled structures. $\mathrm{HAuCl}_{4} /$ peptide samples presented an exponential decay in their correlation curve, which suggests the presence of one predominant population. They are characterized by small particles, with an average size of $50 \mathrm{~nm}$. The $\mathrm{NaBH}_{4}$ peptides mixture samples presented some differences in the correlation curves, indicating that the 
size of the particles is changing. However, a higher uniformity of the data for EGCG hybrids was observed, which form larger particles with size ranging hundreds to the micrometer.

To obtain information about the secondary structure of the peptides in these hybrid systems, CD experiments were performed. Figure 2 shows the CD spectra for all systems analyzed. Considering the spectra for $\mathrm{HAuCl}_{4} /[\mathrm{RF}]_{4}$ (Figure 2a), the samples present a random coil conformation, characterized by a negative band at $194 \mathrm{~nm}$, which corresponds to a $\pi \rightarrow \pi^{*}$ transition, and a positive band at $219 \mathrm{~nm}$, correlated with $\mathrm{n} \rightarrow \pi^{*}$ transition. $^{[40]}$ For $\mathrm{HAuCl}_{4} / \mathrm{P}[\mathrm{RF}]_{4}$, the 1.7 and 2.5 ratios presented three positive bands: at $188 \mathrm{~nm}$ and $190 \mathrm{~nm}$, respectively, which correspond to antiparallel $\beta$-sheet conformation, at $206 \mathrm{~nm}$ and $218 \mathrm{~nm}$, associated, respectively, with $\pi \rightarrow \pi^{*}$ transition and $\mathrm{n} \rightarrow \pi^{*}$ transition, characteristic of phenylalanine amino acids. ${ }^{[41,42]}$ However, a transition to random coil organization was observed for the $\mathrm{HAuCl}_{4} / \mathrm{P}[\mathrm{RF}]_{4}=5.0$ sample, characterized by a negative band located at $188 \mathrm{~nm}$ and two maxima at $200 \mathrm{~nm}$ and $218 \mathrm{~nm}$, as can be seen in Figure $2 b$.

The mixtures of $\mathrm{P}[\mathrm{RF}]_{4} /[\mathrm{RF}]_{4}$ spectra, presented in Figures $2 \mathrm{c}$ and $2 \mathrm{~d}$, had positive bands at $225 \mathrm{~nm}$ and $219 \mathrm{~nm}$, for $\mathrm{NaBH}_{4}$ and EGCG systems, suggesting an antiparallel $\beta$-sheet conformation. It was observed that with increasing $\mathrm{P}[\mathrm{RF}]_{4}$ content, the intensity of the bands decreases, implying less $\beta$-sheet structures are present. 

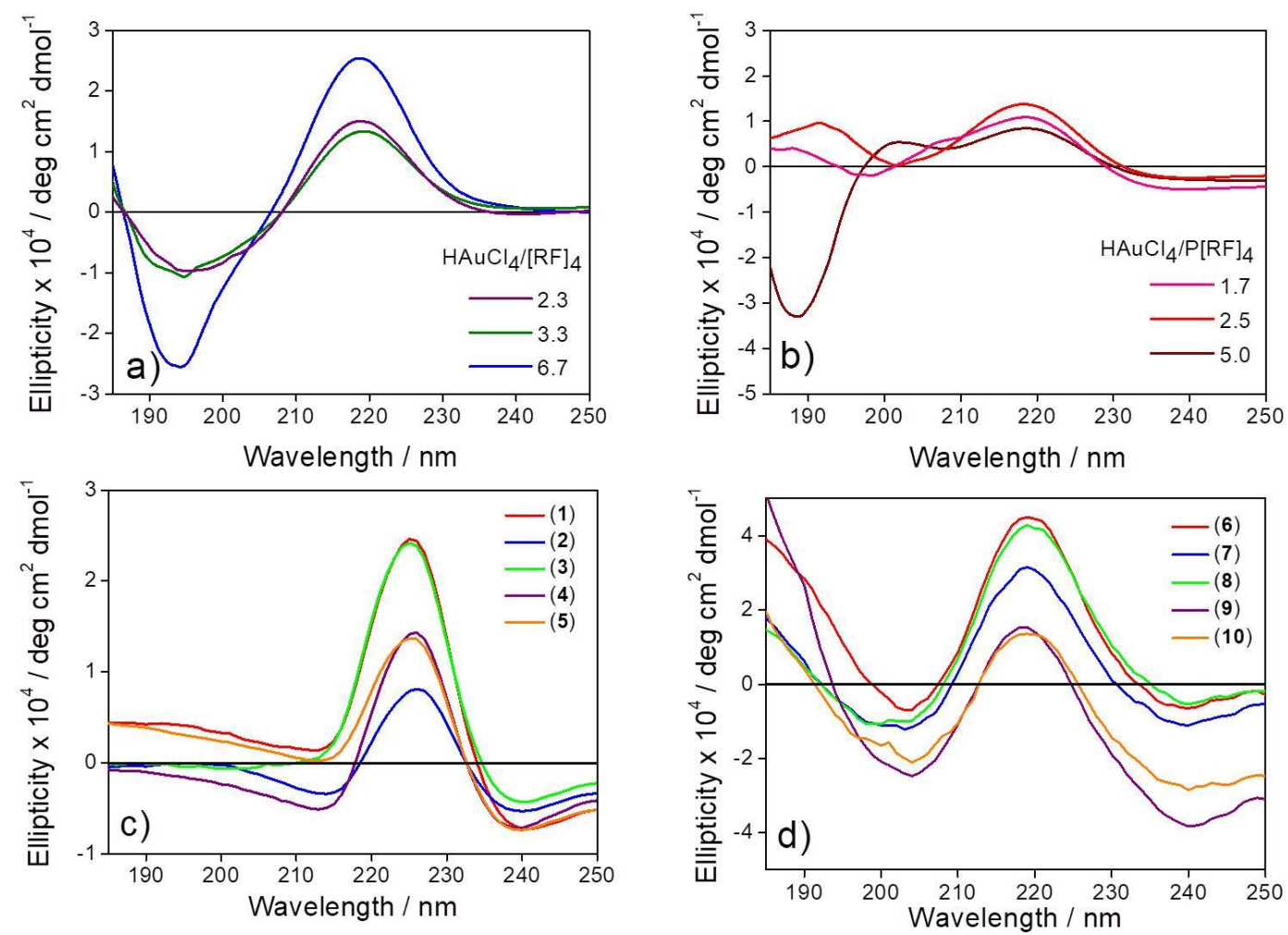

Figure 2. CD spectra of solutions with different proportions of a) $\mathrm{HAuCl}_{4} /[\mathrm{RF}]_{4}$ and b) $\mathrm{HAuCl}_{4} / \mathrm{P}[\mathrm{RF}]_{4}$, both synthesized using $\mathrm{NaBH}_{4}$. The same measurements were performed using different mixtures of $\mathrm{P}[\mathrm{RF}]_{4} /[\mathrm{RF}]_{4}$ in c) $\mathrm{HAuCl}_{4}-\mathrm{NaBH}_{4}$ and d) $\mathrm{HAuCl} \mathrm{AuGCG}_{4}$.

To obtain more detail about the shape and dimensions of nanostructures in the mixtures, SAXS and SANS measurements were performed, and the curves were fitted using the software SASFit. ${ }^{[35]}$ The red curves in the SAXS patterns, presented in Figures 3a and 4a, represent the adjusted form factors. The SAXS data shows the presence of predominant fibril structures, suggesting the formation of fibrils decorated with AuNPs (or alternatively peptide fibrils with a small population of unassociated AuNPs). Systems (1-5) were characterized previously by $\beta$-sheet structures in the micrometer range (see Figure 2); consequently, a long cylindrical shell model (with fixed cylinder length, $1000 \mathrm{~nm}$ ) was used as form factor with a Gaussian size distribution $\left(\sigma_{R}\right)$ of the radius. Also, it was necessary to include only for the samples (1) and (2) a hard-sphere structure factor contribution. Systems containing AuNPs in the absence of peptides, prepared with $\mathrm{NaBH}_{4}$, were fitted using mass fractal Gaussian as a form factor with a Gaussian size distribution. Table 1 summarizes the fitted parameters.

The parameters in Table 1 indicate a gradual decrease of the cylinder radius $(\mathrm{R})$ increasing the $\mathrm{P}[\mathrm{RF}]_{4}$ content in the systems, from $1.9 \mathrm{~nm}$ for sample (1) to $1.1 \mathrm{~nm}$ for (5). 
However, an increase of shell thickness of the cylinders $(\Delta R)$ was observed with increasing $\mathrm{P}[\mathrm{RF}]_{4}$ content. This effect suggests that the proline helps the molecular packing, leading to more compact structures. The model fitting also shows variations in the (electron) scattering length density of the core $\left(\eta_{\text {core }}\right)$ and the shell $\left(\eta_{\text {shell }}\right)$. A considerable increase of the $\eta_{\text {core }}$ was observed in the samples with more $\mathrm{P}[\mathrm{RF}]_{4}$, which also have a lower radius, confirming the higher packing of the peptide molecules in the core of the fibers. The AuNPs system shows fractal clusters with radius (R') $2.3 \mathrm{~nm}$ and fractal dimension $\mathrm{D}=2.0$, with scattering contrast $\left(\mathrm{I}_{0}\right)$ of $5.6 \times 10^{-4}$.

SANS curves for samples at the same concentration as used for SAXS are shown in Figure S3, along with model core-shell cylindrical form factor fits. In this case, a gradual enhancement of the cylinder radius with the increase of $\mathrm{P}[\mathrm{RF}]_{4}$ was observed with almost constant shell thickness (parameters in the inset Table 1). This effect can be associated with the contrast difference caused by the use of a solvent mixture containing $\mathrm{D}_{2} \mathrm{O} / \mathrm{H}_{2} \mathrm{O}(3: 7$, $v / v$ ), which was chosen to enhance the scattering signal. However, an increase of core scattering contrast $\eta_{\text {core }}$ was also observed in the samples with a higher content of $P[R F]_{4}$, which confirms tighter packing in the core again.
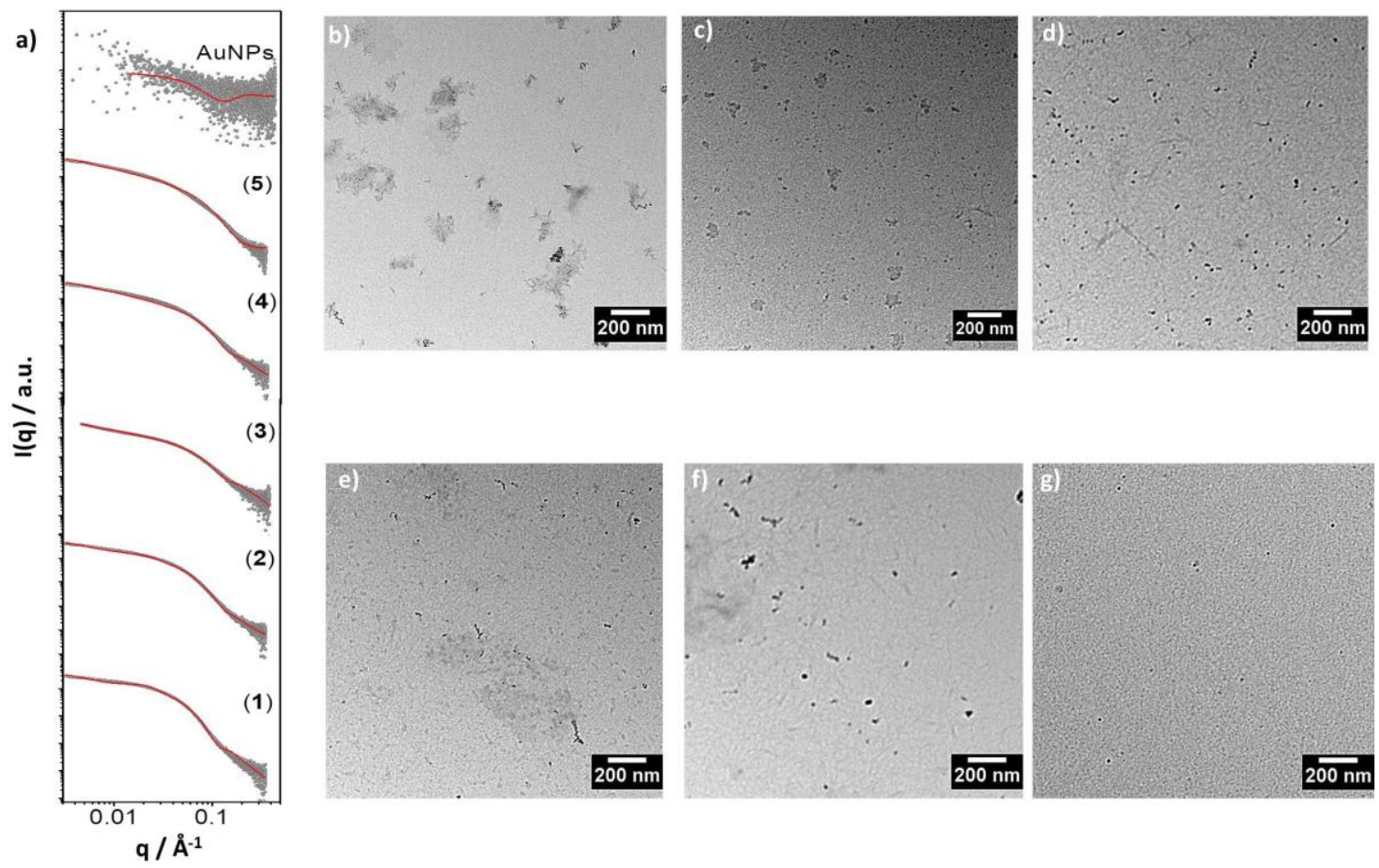

Figure 3. a) SAXS data (grey points) of $\mathrm{P}[\mathrm{RF}]_{4} /[\mathrm{RF}]_{4}$ AuNP hybrids synthesized with $\mathrm{NaBH}_{4}$ in $\mathrm{pH}$ 4. Model fits (red line) using the model described in the text. TEM images of $0.5 \mathrm{wt} \%$ water solutions of b) (1), c) (2), d) (3), e) (4), f) (5) and g) only AuNPs. 
Table 1. Summary of the model parameters obtained from the fitting procedure of SAXS data for peptides mixtures (1), (2), (3), (4), and (5) containing $\mathrm{NaBH}_{4}{ }^{*}$

\begin{tabular}{|c|c|c|c|c|c|}
\hline \multirow[t]{2}{*}{ Samples } & \multicolumn{5}{|c|}{ Long cylindrical shell* } \\
\hline & $\begin{array}{c}\mathrm{R} \\
(\mathbf{n m})\end{array}$ & $\begin{array}{c}\sigma_{\mathrm{R}} \\
(\mathbf{n m})\end{array}$ & $\begin{array}{c}\Delta \mathrm{R} \\
(\mathrm{nm})\end{array}$ & $\eta_{\text {core }}$ & $\eta_{\text {shell }}$ \\
\hline (1) & 1.9 & 0.5 & 0.2 & $1.0 \times 10^{-6}$ & $5.0 \times 10^{-6}$ \\
\hline (2) & 1.4 & 0.7 & 0.7 & $1.3 \times 10^{-6}$ & $1.8 \times 10^{-6}$ \\
\hline (3) & 1.0 & 0.7 & 1.0 & $9.7 \times 10^{-7}$ & $2.0 \times 10^{-6}$ \\
\hline (4) & 1.0 & 0.6 & 0.9 & $1.0 \times 10^{-6}$ & $2.0 \times 10^{-6}$ \\
\hline \multirow[t]{3}{*}{ (5) } & 1.1 & 0.7 & 0.8 & $2.2 \times 10^{-6}$ & $1.0 \times 10^{-6}$ \\
\hline & \multicolumn{5}{|c|}{ Mass fractal Gaussian } \\
\hline & $\begin{array}{c}\mathbf{R}^{\prime} \\
(\mathbf{n m})\end{array}$ & $\begin{array}{c}\sigma_{\mathrm{R}} \\
(\mathbf{n m})\end{array}$ & $\begin{array}{c}D \\
(\mathbf{n m})\end{array}$ & $\mathbf{I}_{\mathbf{0}}$ & \\
\hline AuNPs & 2.3 & 0.4 & 2.0 & $5.6 \times 10^{-4}$ & \\
\hline
\end{tabular}

*The scattering length density of the solvent $\left(n_{\text {solv }}\right)$ was fixed at zero.

TEM images for hybrids (1-5), presented in Figure 3b-f, show the coexistence of small fibers covering the grid surface and spherical gold nanoparticles, with higher contrast, well distributed over the grid, corroborating $C D$ and SAXS results. Increasing the $P[R F]_{4}$ content, more elongated fibers are formed, with length varying from $50 \mathrm{~nm}$ to $200 \mathrm{~nm}$. Globular AuNPs with $20 \mathrm{~nm}$ in diameter were observed, and the interaction between these particles and the peptide fibers leads to the formation of some aggregates. For the sample containing only AuNPs (Figure 3g), only a few nanometer-scale globular nanoparticles were observed.

SAXS data for the peptide mixtures (6-10) was characterized by a -4 power law intensity decay in the low $q$ Guinier regime, suggesting the presence of spheres. For this, the curves were fitted using the sphere form factor, and Gaussian size distribution and the fit parameters are listed in Table 2. This shows an increase of the sphere radius ( $\mathrm{R}$ ') from 1.0 $\mathrm{nm}(\mathbf{6})$ to $2.0 \mathrm{~nm}(\mathbf{1 0})$ and a decrease of the scattering (electron density) contrast (n) with increase in $\mathrm{P}[\mathrm{RF}]_{4}$, corroborating $\mathrm{UV} / \mathrm{V}$ is absorption results. And this effect was more prominent in the AuNPs sample synthesized without the peptides, which had a $2.6 \mathrm{~nm}$ radius. 

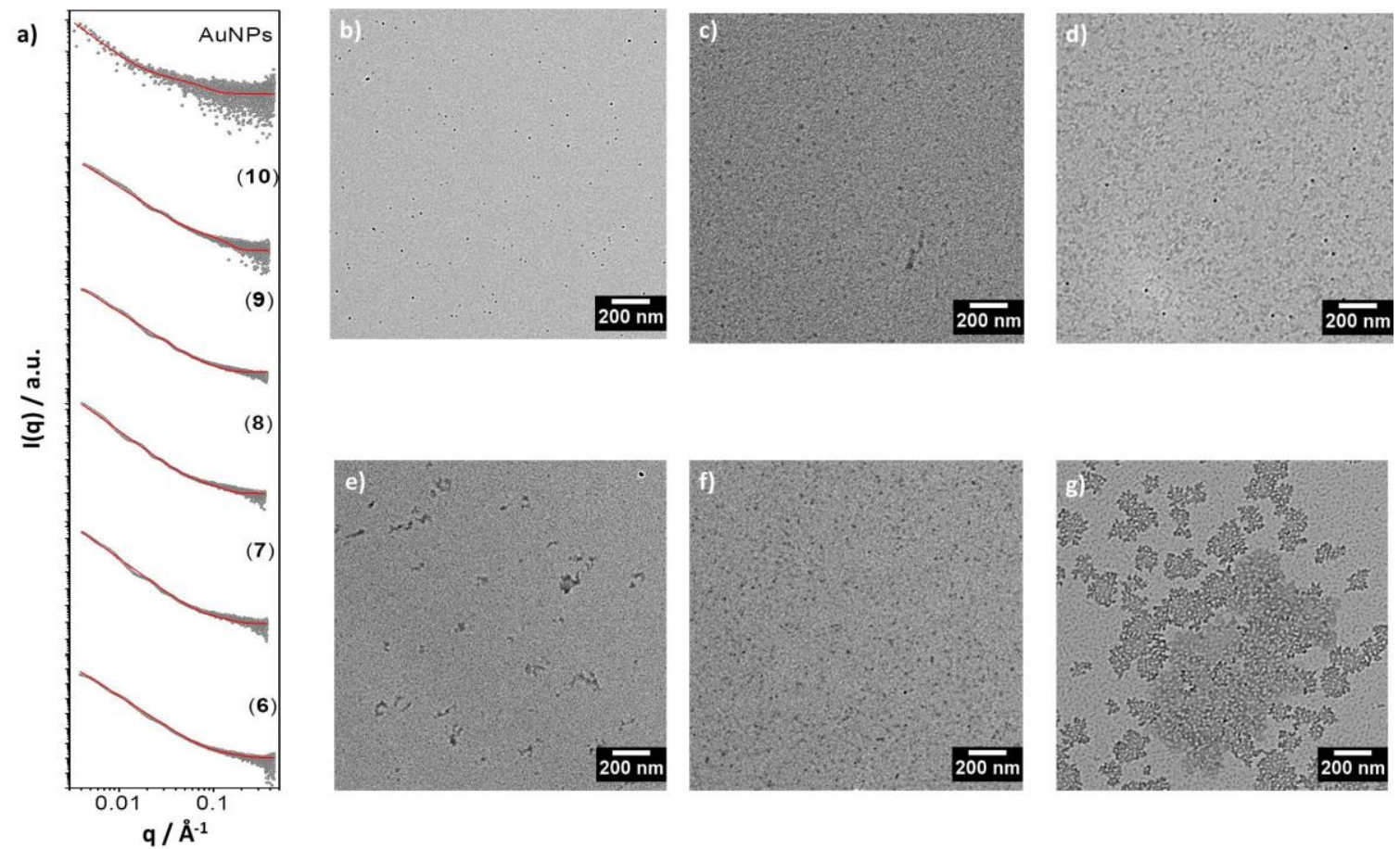

Figure 4. a) SAXS data (grey points) of $P[R F]_{4} /[R F]_{4}$ AuNP hybrids synthesized with EGCG in $\mathrm{pH} 4$. Model fits (red line) using the model described in the text. TEM images of $0.5 \mathrm{wt} \%$ water solutions b) (6), c) (7), d) (8), e) (9), f) (10) and g) only AuNPs.

Table 2. Summary of the model parameters obtained from the fitting procedure of SAXS data for peptides mixtures (6), (7), (8), (9), and (10) using EGCG.

\begin{tabular}{c|ccc}
\hline Samples & \multicolumn{3}{|c}{ Spheres } \\
\hline & $\begin{array}{c}\text { R” } \\
(\mathbf{n m})\end{array}$ & $\begin{array}{c}\boldsymbol{\sigma}_{\mathbf{R}} \\
(\mathbf{n m})\end{array}$ & $\mathbf{\eta}$ \\
\hline$(\mathbf{6})$ & 1.0 & 0.3 & $5.9 \times 10^{-6}$ \\
$(\mathbf{7})$ & 1.5 & 0.3 & $2.4 \times 10^{-6}$ \\
$(\mathbf{8})$ & 1.8 & 0.4 & $1.9 \times 10^{-6}$ \\
$(\mathbf{9})$ & 2.0 & 0.3 & $1.2 \times 10^{-6}$ \\
$(\mathbf{1 0})$ & 2.0 & 0.2 & $2.4 \times 10^{-6}$ \\
AuNPs & 2.6 & 0.5 & $3.1 \times 10^{-7}$ \\
\hline
\end{tabular}

For the EGCG systems (Figures 4b-f), TEM images revealed the presence of spherical AuNPs with a size of approximately $20 \mathrm{~nm}$, and as for the $\mathrm{NaBH}_{4}$ samples, the interaction of these nanoparticles is higher with increasing $\mathrm{P}[\mathrm{RF}]_{4}$ content, since larger aggregates are observed. However, the AuNPs sample showed a higher level of organization of these globular particles, suggesting that the coalescence process is more pronounced, forming 
aggregates with sizes ranging from $\mathrm{nm}$ to $\mu \mathrm{m}$. These results corroborate with DLS and SAXS results presented previously.

\subsection{Colorimetric analysis of $\mathrm{Cu}^{2+}$}

The addition of the salt into the peptide hybrid-functionalized gold nanoparticles promoted changes in the solution colors, varying initially from red to blue (see Figure S4). To verify possible differences in the size and morphology of the gold aggregates, UV/Vis absorption, and TEM analyses were performed. Figure S5 shows a shifting of the gold plasmonic resonance band, from $520 \mathrm{~nm}$ (peak 1) to $544-562 \mathrm{~nm}$, with salt addition and an increase of the $600 \mathrm{~nm}$ band (peak 2), which indicates a difference in the particle morphology. ${ }^{[20]}$ The redshift of the plasmonic band and the appearance of the $600 \mathrm{~nm}$ band show an increase of the gold nanoparticles size. ${ }^{[43]}$ This effect was confirmed by changes in the colors of the solutions from red to blue, as can be seen in Figure S4. The sensitivity of the colorimetric assay to distinct concentrations of $\mathrm{Cu}^{2+}$ in solutions containing the hybrids was investigated considering the absorption ratio $\left(\mathrm{A}_{600} / \mathrm{A}_{520}\right)$ as a function of the metal ion concentration. A linear fit was used, and the equations are shown in Figure 5.

TEM images, presented in Figure 5, confirm morphological changes of the hybrids with the metal ion interaction, establishing the UV/Vis absorption results. In all systems, aggregation effects are prominent, resulting in some cases in the formation of micrometer aggregates. This aggregation process suggests that the gold-peptide hybrids interact with the metal ions, capturing them and, consequently, forming large aggregates, which can separate from the rest of the solution.

To evaluate the sensitivity and minimum concentration of $\mathrm{Cu}^{2+}$ that can be detected by this colorimetric method, a progression of metal ion concentrations from 7.0 to $223 \mu \mathrm{mol} \cdot \mathrm{L}^{-}$ ${ }^{1}$ was added to all samples in aqueous solution, as shown in Figure 5. We observed a gradual blue-to-red color change when the concentration of $\mathrm{Cu}^{2+}$ was increased. The sensitivity of the colorimetric assay was determined by the absorption ratio $\left(\mathrm{A}_{600} / \mathrm{A}_{520}\right)$ as a function of the metal ion concentration, showing a good linear correlation coefficient for the AuNP sensor (6), with a detection limit (LD) of $0.19 \mu \mathrm{mol} \mathrm{L}^{-1}$ based on the $3 \sigma$ error on the slope. This value is quite reasonable compared to other colorimetric sensors for $\mathrm{Cu}^{2+}$ described in the literature (see Table 3). 

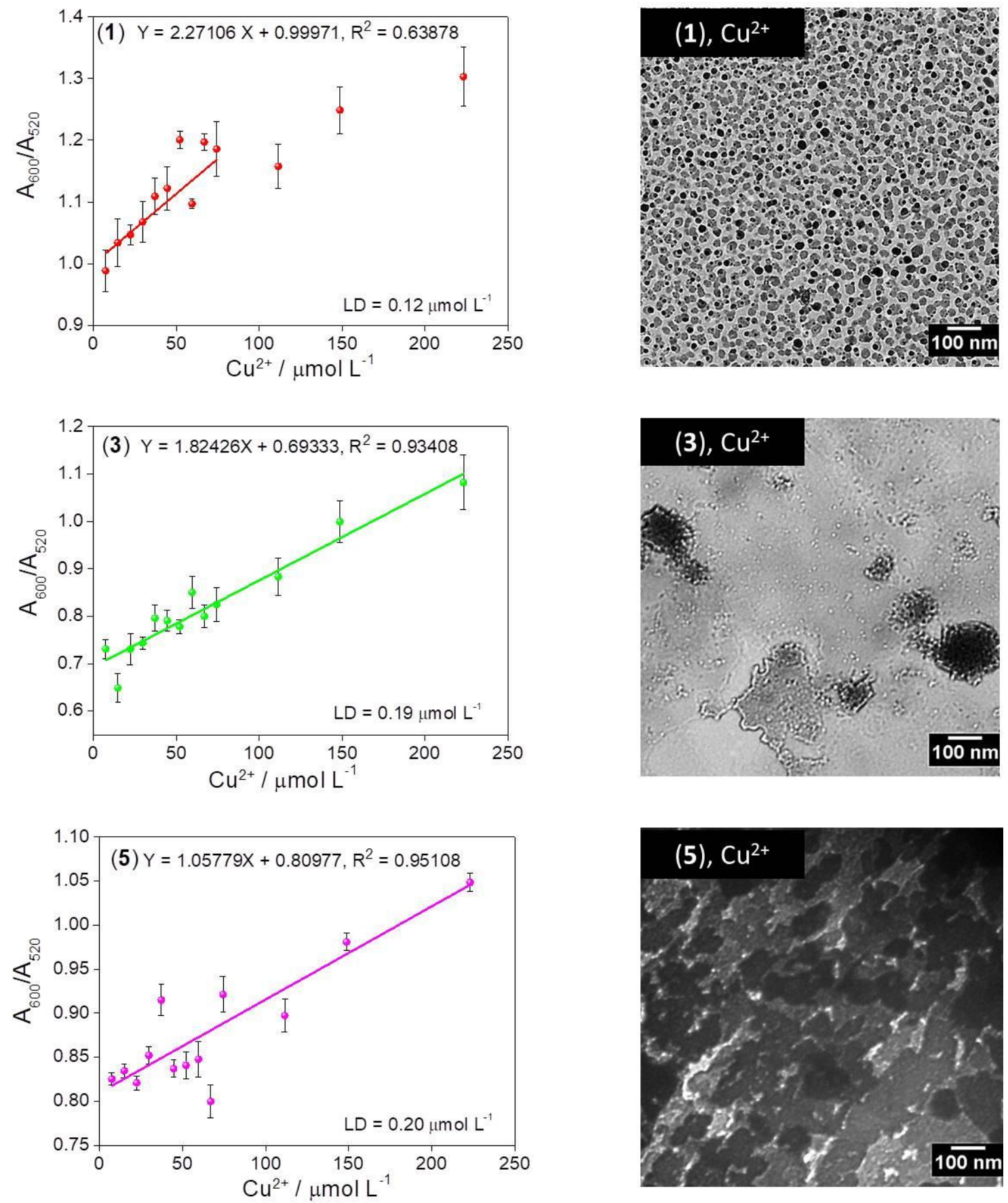

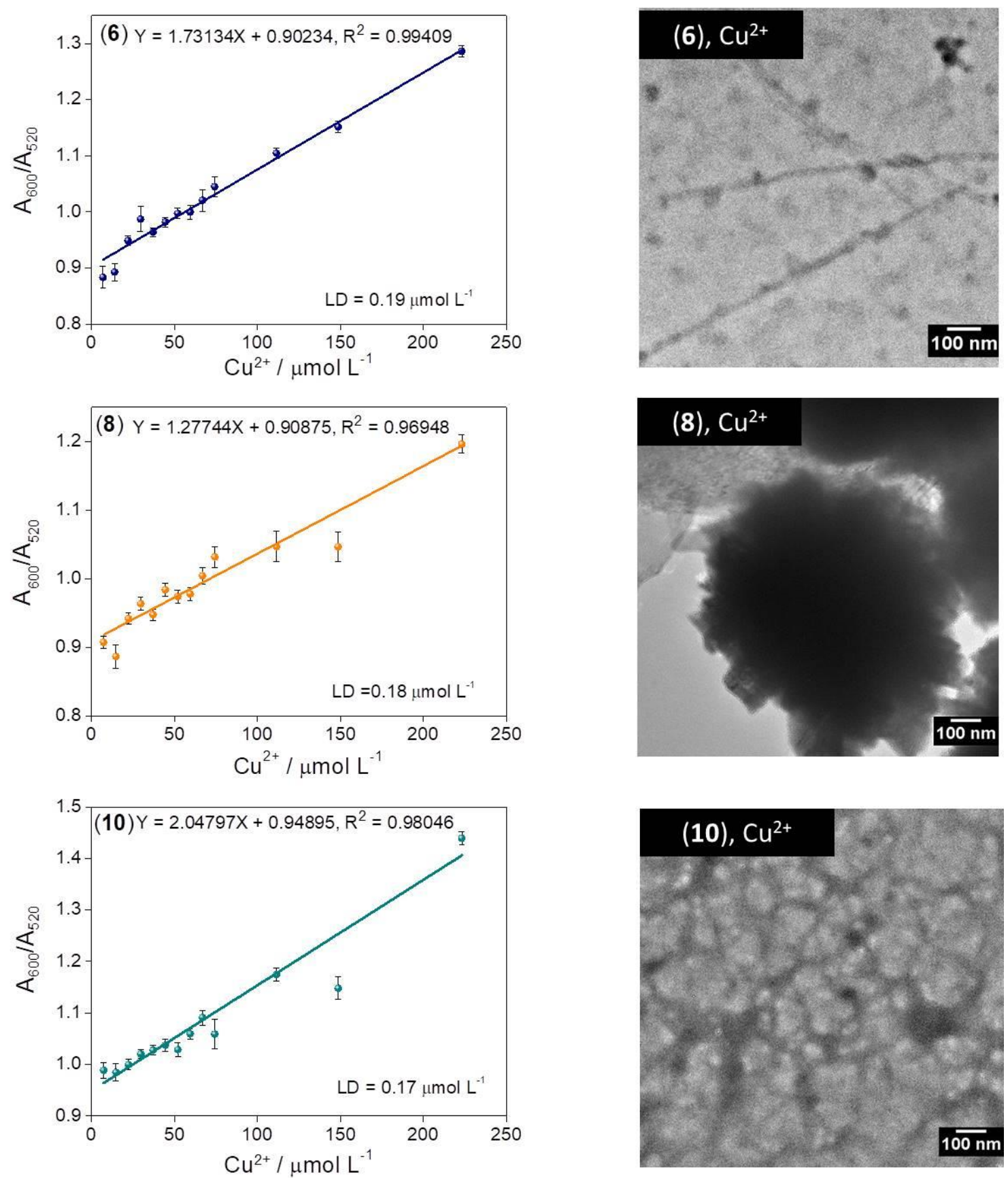

Figure 5. Absorption ratios $\left(\mathrm{A}_{600} / \mathrm{A}_{520}\right)$ as a function of the metal ion concentration in solution. TEM images of the systems $(\mathbf{1}, \mathbf{3}, \mathbf{5}, \mathbf{6}, \mathbf{8}$, and $\mathbf{1 0})$ in the presence of solutions containing $75 \mu \mathrm{mol} \cdot \mathrm{L}^{-}$ ${ }^{1}$ of $\mathrm{Cu}^{2+}$. 
Table 3. Comparison of proposed $\mathrm{Cu}^{2+}$ sensor with other reported colorimetric sensors in the literature.

\begin{tabular}{ccc}
\hline Recognition systems & $\begin{array}{c}\text { Detection limit } \\
\left(\boldsymbol{\mu} \mathbf{m o l ~ L}^{-1}\right)\end{array}$ & References \\
\hline Amyloid-like peptide (6) / AuNPs & 0.19 & This study \\
Cysteine-(Glutamine) $/$ AuNPs & 1.0 & {$[44]$} \\
L-Cysteine / AuNPs & 2.2 & {$[45]$} \\
L-Cysteine / Gold nanorod & 0.34 & {$[46]$} \\
DNAzyme / AuNPs & 0.29 & {$[47]$} \\
Escherichia coli / AuNPs & 0.40 & {$[48]$} \\
DNA / Click chemistry & 0.20 & {$[49]$} \\
Starch-stabilized silver nanoparticles & 0.63 & {$[50]$} \\
In situ formation of silver nanoparticles & 0.25 & {$[51]$} \\
DNA / AuNPs & 20 & {$[52]$} \\
Thermally treated AuNPs & 0.040 & {$[53]$} \\
Azide-tagged AuNPs & 1.80 & {$[54]$} \\
Triazole / Click chemistry & 10 & {$[55]$} \\
Polythiophene / Click chemistry & 3.0 & {$[56]$} \\
Dopamine / AuNPs & 1.4 & {$[57]$} \\
Catalytic leaching / AuNPs & 0.70 & {$[58]$} \\
Copper catalysis / AgNPs & 0.75 & {$[51]$} \\
Casein peptide / AgNPs & 0.16 & \\
\hline
\end{tabular}

To validate the UV/Vis data and confirm the metal ion association with the peptide, dispersive Raman spectra were recorded in the absence and presence of $\mathrm{Cu}^{2+}$, and are shown in Figure 6. Table S2 presents all the vibrational bands assignment. ${ }^{[60,70]}$ The peaks at 1586,1606 , and $1674 \mathrm{~cm}^{-1}$ confirm $\beta$-turn conformation, supporting the $\mathrm{CD}$ data. $\mathrm{A}$ linear electronic Raman background up to $200 \mathrm{~cm}^{-1}$ was observed for all EGCG spectra, and for the mixture of $\mathrm{P}[\mathrm{RF}]_{4} /[\mathrm{RF}]_{4}(5: 5, v / v)$ with $\mathrm{NaBH}_{4}$, as shown in Figure $6 \mathrm{~b}$. This effect is associated with the fluorescence signal.

The insertion of $\mathrm{Cu}^{2+}$ ions in these systems promoted the appearance of two sharp peaks at $105-109 \mathrm{~cm}^{-1}$ and $160-174 \mathrm{~cm}^{-1}$, characterized by the hydrogen-bond vibrations and N-Cu-N angle bend, respectively. ${ }^{[68,69]}$ The band at $214 \mathrm{~cm}^{-1}$ is associated with the oriented crystal growth $\mathrm{CuO} .{ }^{[70]}$ These bands confirm the self-assembly changes by the interaction of the $\mathrm{Cu}^{2+}$ ions, as observed previously by TEM. Another considerable effect is the concentration of metal ions solutions. As the $\mathrm{Cu}^{2+}$ concentration increased more 
prominent and defined were the peaks, suggesting an enhancement of the surface-enhanced Raman scattering (SERS) by the signal amplification of the AuNPs resonance band.

a)

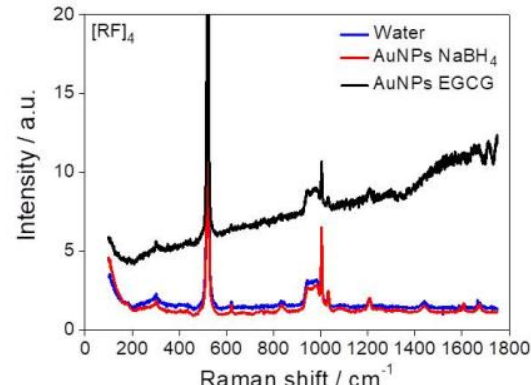

c)

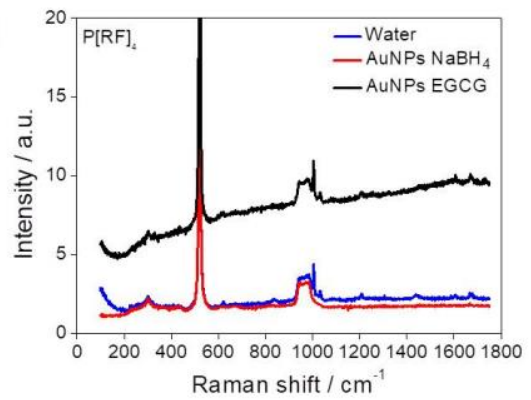

e)



g)

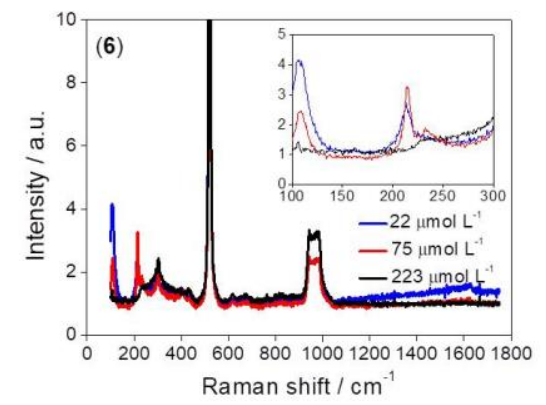

b)

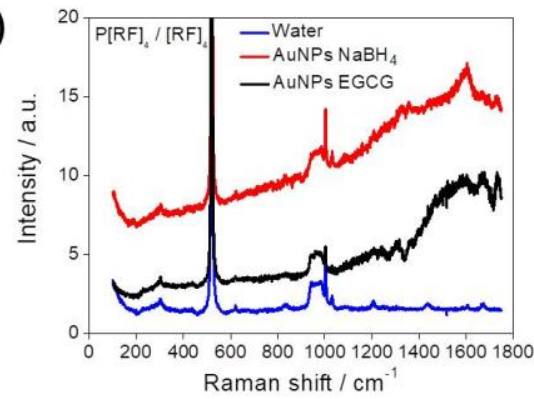

d)

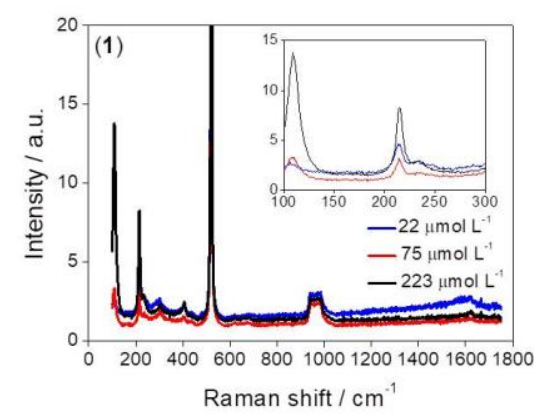

f)

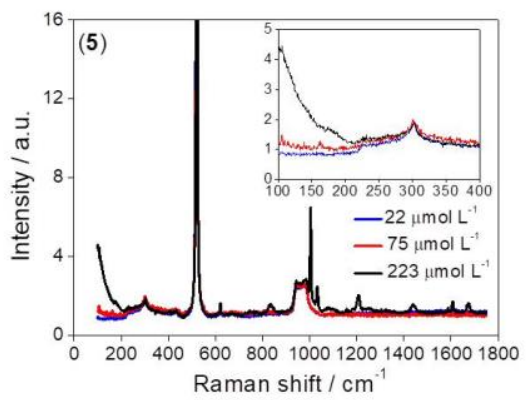

h)

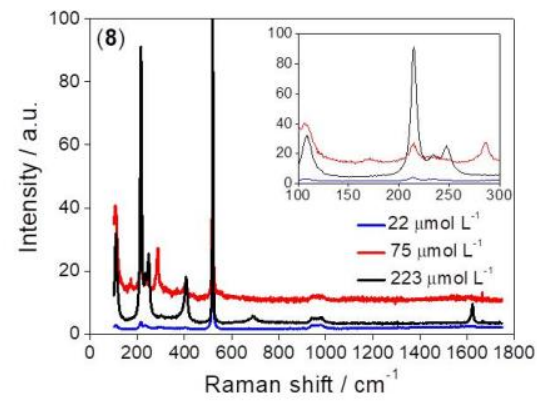




Figure 6. Dispersive Raman spectra of $22 \mu \mathrm{mol} \cdot \mathrm{L}^{-1}$ solutions of a) $\left.[\mathrm{RF}]_{4}, \mathrm{~b}\right) \mathrm{P}[\mathrm{RF}]_{4} /[\mathrm{RF}]_{4}(5: 5, v / v)$, and c) $\mathrm{P}[\mathrm{RF}]_{4}$ in the absence and the presence of AuNPs. Comparison of the dispersive Raman spectra of the systems d) (1), e) (3), f) (5), g) (6), h) (8) and i) (10) with solutions containing 22, 75 and $223 \mu \mathrm{mol} \cdot \mathrm{L}^{-1}$ of $\mathrm{Cu}^{2+}$. The insert shows the $\mathrm{Cu}^{2+}$ peaks.

In this case, copper(II) ions can coordinate with the amine or carboxylic groups present in the peptide-binding core. ${ }^{[71]}$ Considering that our systems are composed of hybrids with gold nanoparticles nucleated with the $\beta$-amyloid peptides, the insertion of the $\mathrm{Cu}^{2+}$ promotes an enhancement of the aggregation of nanoparticles, due to the complexation process with functional groups from amino acid residues, as shown in Figure 7. Also, the SERS-enhanced bands at 170, 242 and $401 \mathrm{~cm}^{-1}$, which are all absent before the $\mathrm{Cu}^{2+}$ assembly, are assignable to $\mathrm{N}-\mathrm{Cu}-\mathrm{N}, \mathrm{Cu}-\mathrm{Cl}$, and $\mathrm{Cu}-\mathrm{O}$ vibrations, respectively, indicating that these bonds are aligned close to perpendicular to the gold nanoparticles surface in the $\mathrm{Cu}^{2+}$ (peptide) self-assembled complexes. A similar study showed the same results for $L$ Cysteine adsorbed on gold nanoparticles. ${ }^{[45]}$
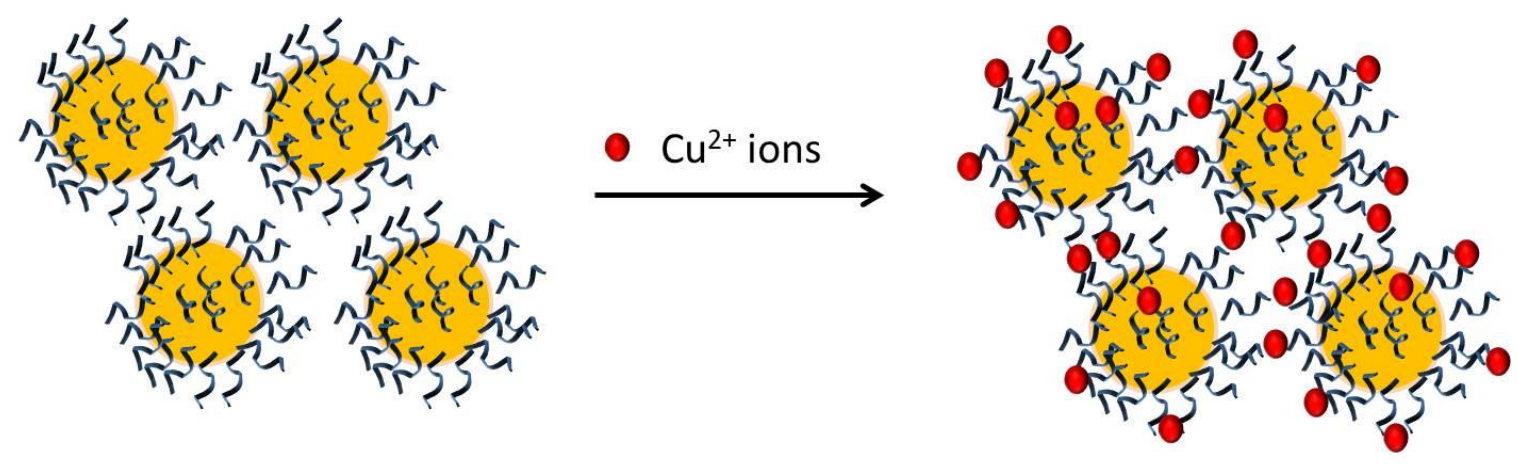

Figure 7. Schematic representation of the $\mathrm{Cu}^{2+}$ coordination to the AuNP-peptide conjugates.

The affinity site of the sensor proposed in this work was also tested for nickel ions under all experimental conditions. The Raman spectra results, considering systems (3) and (8), clearly show that this ion does not interfere in the sensor response using the same procedure. The comparison of the $\mathrm{Cu}^{2+}$ and $\mathrm{Ni}^{2+}$ Raman bands is shown in Figure S6. Additionally, the proposed method shows applicability to the analysis of a real water sample. For this, $300 \mu \mathrm{L}$ of water (rain and tap) were mixed with $80 \mu \mathrm{L}$ of AuNP sensors $(\mathbf{1}, \mathbf{3}, \mathbf{5}, \mathbf{6}, \mathbf{8}$, and 10), respectively, and the mixtures were analyzed by UV/Vis spectrophotometry. The obtained results in Table S3 show approximately $7.0 \mu \mathrm{mol} \mathrm{L}^{-1}$ of $\mathrm{Cu}^{2+}$ in the rain, and $15 \mu \mathrm{mol} \mathrm{L} \mathrm{L}^{-1}$ of $\mathrm{Cu}^{2+}$ in the tap water. Thus, these materials could act as sensitive metal ion detectors and as residual water cleaners. 


\section{CONCLUSIONS}

We have shown that arginine/phenylalanine based peptides can be used to control the aggregation of gold nanoparticles in different ways depending on the chemical conditions of the colloidal solutions. The peptides form nanofibrils with $\beta$-sheet secondary structures, which can nucleate the deposition of gold nanoparticles. The use of $\mathrm{NaBH}_{4}$ or EGCG as AuNP reductant leads to distinct morphologies of gold-decorated fibrils or spherical gold NP aggregates, respectively

The dimensions of the nanofibrils observed in solutions with $\mathrm{NaBH}_{4}$ reduced AuNPs were carefully analyzed via form factor fits of solution SAXS data. This shows a decrease in the cylinder core radius with increasing $\mathrm{P}[\mathrm{RF}]_{4}$ content in the mixture of the peptides. Use of a mix of $[R F]_{4}$ and $\mathrm{P}[\mathrm{RF}]_{4}$ peptides are shown to be viable means to control the width of fibrils decorated with gold NPs. In contrast, EGCG nucleates spherical AuNPs in the presence of the peptide mixtures.

The AuNPs are well dispersed in solution at acidic $\mathrm{pH}$, a condition that stabilizes the gold nanoparticles with a radius approximately 10-20 $\mathrm{nm}$. Colorimetric assays show these hybrids can act as probes to identify $\mathrm{Cu}^{2+}$ ions in solution, highlighting their efficiency in metal ion detection in water. These peptide AuNP systems show great promise as sensitive detection systems for metal ion analysis.

\section{SUPPORTING INFORMATION SUMMARY}

Additional characterization data are provided in supporting information.

\section{CONFLICT OF INTEREST}

The authors declare no competing financial interests.

\section{ACKNOWLEDGMENTS}

This work was supported by FAPESP (grant no. 2017/02317-2) and CNPq (grant no. 302923/2015-2). INCT in Bioanalytics (FAPESP grant no. 2014/50867-3 and CNPq grant no. 465389/2014-7) is kindly acknowledged for the grants. J.N.B.D.P. acknowledges FAPESP (project number 2015/20446-9 and 2018/12535-0) for a doctoral fellowship and the research internship abroad program (BEPE). B.B.G. acknowledges FAPESP (project number 2018/05888-3) for a doctoral and post-doctoral fellowship. We thank Diamond for the award of beamtime on beamline B21 (SM21470-2 and SM22925-1) and ISIS for the 
award of beamtime on LARMOR (reference 1910005) and James Doutch for assistance. IWH acknowledges EPSRC for Platform grant EP/L020599/1. The authors are grateful for access to the Chemical Analysis Facility at the University of Reading.

\section{REFERENCES}

1. Cipriano, T. C.; Takahashi, P. M.; de Lima, D.; Oliveira Jr., V. X.; Souza, J. A.; Martinho, H.; Alves, W. A. Spatial Organization of Peptide Nanotubes for Electrochemical Devices. J. Mat. Sci. 2010, 45, 5101-5108.

2. Matos, I. O.; Alves, W. A. Electrochemical Determination of Dopamine Based on Self-Assembled Peptide Nanostructure. ACS Appl. Mater. Interfaces. 2011, 3, 4437-4443.

3. Bianchi, R. C.; Silva, E. R.; Dall'Antonia, L. H.; Ferreira, F. F.; Alves, W. A. A Nonenzymatic Biosensor Based on Gold Electrodes Modified with Peptide SelfAssemblies for Detecting Ammonia and Urea Oxidation. Langmuir. 2014, 30, 11464-11473.

4. Sousa, C. P.; Coutinho-Neto, M. D.; Liberato, M. S.; Kubota, L. T.; Alves, W. A. Self-Assembly of Peptide Nanostructures onto an Electrode Surface for Nonenzymatic Oxygen Sensing. J. Phys. Chem. C. 2015, 119, 1038-1046.

5. Souza, M. I.; Jaques, Y. M.; Andrade, G. P.; Ribeiro, A. O.; Silva, E. R.; Fileti, E. E.; Ávilla, E. S.; Pinheiro, M. V. B.; Krambrock, K.; Alves, W. A. Structural and Photophysical Properties of Peptide Micro/Nanotubes Functionalized with Hypericin. J. Phys. Chem. B. 2013, 117, 2605-2614.

6. Yan, X.; Li, J.; Möhwald, H. Self-assembly of Hexagonal Peptide Microtubes and Their Optical Waveguiding. Adv. Mater. 2011, 23, 2796-2801.

7. Khanra, S.; Cipriano, T.; Lam, T.; White, T. A.; Fileti, E. E.; Alves, W. A.; Guha, S. Self-Assembled Peptide-Polyfluorene Nanocomposites for Biodegradable Organic Electronics. Adv. Mater. Interfaces. 2015, 2, 1500265.

8. Gazit, E. Self-Assembly of Short Peptides for Nanotechnological Applications, in NanoBioTechnology: BioInspired Devices and Materials of the Future, Shoseyov, O.; Levy, I. Editors. 2008, Humana Press: Totowa, NJ, 385-395.

9. Guo, C.; Luo, Y.; Zhou, R.; Wei, G. Probing the Self-Assembly Mechanism of Diphenylalanine-Based Peptide Nanovesicles and Nanotubes. ACS Nano. 2012, 6, 3907-3918. 
10. Ulijn, R.V.; Smith, A. M. Designing Peptide Based Nanomaterials. Chem. Soc. Rev. 2008, 37, 664-675.

11. Silva, E. R.; Listik, E.; Han, S. W.; Alves, W. A.; Soares, B. M.; Reza, M.; Ruokolainen, J.; Hamley, I. W. Sequence Length Dependence in Arginine/Phenylalanine Oligopeptides: Implications for Self-assembly and Cytotoxicity. Biophy. Chem. 2018, 233, 1-12.

12. Decandio, C. C.; Silva, E. R.; Hamley, I. W.; Castelletto, V.; Liberato, M. S.; Oliveira Jr., V. X.; Oliveira, C. L. P.; Alves, W. A. Self-Assembly of a Designed Alternating Arginine/Phenylalanine Oligopeptide. Langmuir. 2015, 31, 4513-4523.

13. Liberato, M. S.; Kogikoski Jr., S.; Silva, E. R.; Coutinho-Neto, M. D.; Scott, L. P. B.; Silva, R. H.; Oliveira Jr., V. X.; Ando, R. A.; Alves, W. A. Self-Assembly of Arg-Phe Nanostructures via the Solid-Vapor Phase Method. J. Phys. Chem. B. 2013, 117, 733-740.

14. Pelin, J. N. B. D.; Gerbelli, B. B.; Soares, B. M.; Aguilar, A. M.; Alves, W. A. Amyloidogenic Model Peptides as Catalysts for Stereoselective Aldol Reactions. Catal. Sci. Technol. 2019, 9, 4304-4313.

15. de la Rica, R.; Chow, L. W.; Horejs, C. M.; Mazo, M.; Chiappini, C.; Pashuck, E. T.; Bitton, R.; Stevens, M. M. A Designer Peptide as a Template for Growing Au Nanoclusters. Chem. Commun. 2014, 50, 10648-10650.

16. Chavva, S. R.; Deshmukh, S. K.; Kanchanapally, R.; Tyagi, N.; Coym, J. W.; Singh, A. P.; Singh, S. Epigallocatechin Gallate-Gold Nanoparticles Exhibit Superior Antitumor Activity Compared to Conventional Gold Nanoparticles: Potential Synergistic Interactions. Nanomater. 2019, 9, 396-411.

17. Nune, S. K.; Chanda, N.; Shukla, R.; Katti, K.; Kulkarni, R. R.; Thilakavathi, S.; Mekapothula, S.; Kannan, R.; Katti, K. V. Green Nanotechnology from Tea: Phytochemicals in Tea as Building Blocks for Production of Biocompatible Gold Nanoparticles. J. Mater. Chem. 2009, 19, 2912-2920.

18. Mukherjee, S.; Ghosh, S.; Das, D. K.; Chakraborty, P.; Choudhury, S.; Gupta, P.; Adhikary, A.; Dey, S.; Chattopadhyay, S. Gold-conjugated Green Tea Nanoparticles for Enhanced Anti-tumor Activities and Hepatoprotection Synthesis, Characterization and in vitro Evaluation. J. Nutr. Biochem. 2015, 26, 1283-1297.

19. Sharma, R. K.; Gulati, S.; Mehta, S. Preparation of Gold Nanoparticles Using Tea: A Green Chemistry Experiment. J. Chem. Educ. 2012, 89, 1316-1318. 
20. Zhang, M.; Liu, Y. Q.; Ye, B. C. Colorimetric Assay for Parallel Detection of $\mathrm{Cd}^{2+}$, $\mathrm{Ni}^{2+}$ and $\mathrm{Co}^{2+}$ Using Peptide-modified Gold Nanoparticles. Analyst. 2012, 137, 601-607.

21. Lin, Z.; Li, X.; Kraatz, H.-B. Impedimetric Immobilized DNA-Based Sensor for Simultaneous Detection of $\mathrm{Pb} 2+, \mathrm{Ag}+$, and $\mathrm{Hg} 2+$. Anal. Chem. 2011, 83, 68966901.

22. Guo, Y.; Wang, Z.; Qu, W.; Shao, H.; Jiang, X. Colorimetric Detection of Mercury, Lead and Copper Ions Simultaneously Using Protein-Functionalized Gold Nanoparticles. Biosens. Bioelectron. 2011, 26, 4064-4069.

23. Liu, J; Lu, Y. A Colorimetric Lead Biosensor Using DNAzyme-Directed Assembly of Gold Nanoparticles. J. Am. Chem. Soc. 2003, 125, 6642-6643.

24. Li, X.; Wang, J.; Sun, L.; Wang, Z. Gold Nanoparticle-Based Colorimetric Assay for Selective Detection of Aluminium Cation on Living Cellular Surfaces. Chem. Commun. 2010, 46, 988-990.

25. Xu, Y.; Deng, L.; Wang, H.; Ouyang, X.; Zheng, J.; Li, J.; Yang, R. Metal-Induced Aggregation of Mononucleotides-Stabilized Gold Nanoparticles: an Efficient Approach for Simple and Rapid Colorimetric Detection of $\mathrm{Hg}$ (ii). Chem. Commun. 2011, 47, 6039-6041.

26. Dong, H.; Shen, W.; Cheung, M. T.; Liang, Y.; Cheung, H. Y.; Allmaier, G.; KinChung Au, O.; Lam, Y. W. Rapid Detection of Apoptosis in Mammalian Cells by Using Intact Cell MALDI Mass Spectrometry. Analyst. 2011, 136, 5181-5189.

27. Zhang, M.; Liu, Y. Q.; Ye, B. C. Colorimetric Assay for Sulfate Using PositivelyCharged Gold Nanoparticles and Its Application for Real-Time Monitoring of Redox Process. Analyst. 2011, 136, 4558-4562.

28. Zhang, M.; Liu, Y. Q.; Ye, B. C. Rapid and Sensitive Colorimetric Visualization of Phthalates Using UTP-Modified Gold Nanoparticles Cross-Linked by Copper(ii). Chem. Commun. 2011, 47, 11849-11851.

29. Lévy, R.; Thanh, N. T. K.; Doty, C.; Hussain, I.; Nichols, R. J.; Schiffrin, D. J.; Brust, M.; Fernig, D. G. Rational and Combinatorial Design of Peptide Capping Ligands for Gold Nanoparticles. J. Am. Chem. Soc. 2004, 126, 10076-10084.

30. Bavoso, A.; Ostuni, A.; Battistuzzi, G.; Menabue, L.; Saladini, M.; Sola, M. Metal Ion Binding to a Zinc Finger Peptide Containing the Cys-X2-Cys-X4-His-X4-Cys Domain of a Nucleic Acid Binding Protein Encoded by theDrosophilaFw-Element. Biochem. Biophys. Res. Commun. 1998, 242, 385-389. 
31. Lee, H. S.; Spraggon, G.; Schultz, P. G.; Wang, F. Genetic Incorporation of a MetalIon Chelating Amino Acid into Proteins as a Biophysical Probe. J. Am. Chem. Soc. 2009, 131, 2481-2483.

32. Tanaka, T.; Mizuno, T.; Fukui, S.; Hiroaki, H.; Oku, J.; Kanaori, K.; Tajima, K.; Shirakawa, M. Two-Metal Ion, Ni(II) and Cu(II), Binding $\alpha$-Helical Coiled Coil Peptide. J. Am. Chem. Soc. 2004, 126, 14023-14028.

33. Carpino, L. A.; Han, G. Y. 9-Fluorenylmethoxycarbonyl Function, A New BaseSensitive Amino-Protecting Group. J. Am. Chem. Soc. 1970, 92, 5748-5749.

34. Kaiser, E.; Colescott, R. L.; Bossinger, C. D.; Cook, P. I. Color Test for Detection of Free Terminal Amino Groups in the Solid-Phase Synthesis of Peptides. Anal. Biochem. 1970, 34, 595-598.

35. Bressler, I.; Kohlbrecher, J.; Thünemann, A. F. SASfit: A Tool for Small-Angle Scattering Data Analysis Using a Library of Analytical Expressions. J. Appl. Crystallogr. 2015, 48, 1587-1598.

36. Eustis, S.; El-Sayed, M. A. Why Gold Nanoparticles are More Precious Than Pretty Gold: Noble Metal Surface Plasmon Resonance and Its Enhancement of the Radiative and Nonradiative Properties of Nanocrystals of Different Shapes. Chem. Soc. Rev. 2006, 35, 209-217.

37. Chen, R. F. Measurements of Absolute Values in Biochemical Fluorescence Spectroscopy. J. Res. Natl. Bureau Stand. 1972, 76, 593-606.

38. Jain, P. K.; Huang, X.; El-Sayed, I. H.; El-Sayed, M. A. Review of Some Interesting Surface Plasmon Resonance-enhanced Properties of Noble Metal Nanoparticles and Their Applications to Biosystems. Plasmonics. 2007, 2, 107-118.

39. Sondi, I.; Goia, D. V.; Matijević, E. Preparation of Highly Concentrated Stable Dispersions of Uniform Silver Nanoparticles. J. Colloid Interf. Sci. 2003, 260, 7581.

40. Ranjbar, B.; Gill, P. Circular Dichroism Techniques: Biomolecular and Nanostructural Analyses- A Review. Chem. Biol. Drug Des. 2009, 74, 101-120.

41. Krysmann, M. J.; Castelletto, V.; Hamley, I. W. Fibrillisation of Hydrophobically Modified Amyloid Peptide Fragments in an Organic Solvent. Soft Matter. 2007, 3, 1401-1406.

42. Yan, X.; Cui, Y.; He, Q.; Wang, K.; Li, J. Organogels Based on Self-Assembly of Diphenylalanine Peptide and Their Application To Immobilize Quantum Dots. Chem. Mater. 2008, 20, 1522-1526. 
43. de Vries, W. C.; Niehues, M.; Wissing, M.; Würthwein, T.; Mäsing, F.; Fallnich, C.; Studer, A.; Ravoo, B. J. Photochemical Preparation of Gold Nanoparticle Decorated Cyclodextrin Vesicles with Tailored Plasmonic Properties. Nanoscale. 2019, 11, 9384-9391.

44. Chen, H.; Zhang, J.; Liu, X.; Gao, Y.; Ye, Z.; Li, G. Colorimetric Copper(ii) Ion Sensor Based on the Conformational Change of Peptide Immobilized onto the Surface of Gold Nanoparticles. Anal. Methods. 2014, 6, 2580-2585.

45. Weng, Z.; Wang, H.; Vongsvivut, J.; Li, R.; Glushenkov, A. M.; He, J.; Chen, Y.; Barrow, C. J.; Yang, W. Self-Assembly of Core-Satellite Gold Nanoparticles for Colorimetric Detection of Copper Ions. Anal. Chim. Acta. 2013, 803, 128-134.

46. Liu, J.-M.; Wang, H.-F.; Yan, X.-P. A Gold Nanorod Based Colorimetric Probe for the Rapid and Selective Detection of Cu2+ Ions. Analyst. 2011, 136, 3904-3910.

47. Wang, Y.; Yang, F.; Yang, X. Label-Free Colorimetric Biosensing of Copper(II) Ions with Unimolecular Self-Cleaving Deoxyribozymes and Unmodified Gold Nanoparticle Probes. Nanotechnology. 2010, 21, 205502-205508.

48. Wang, Y.; Wang, L.; Su, Z.; Xue, J.; Dong, J.; Zhang, C.; Hua, X.; Wang, M.; Liu, F. Multipath Colourimetric Assay for Copper(II) Ions Utilizing MarR Functionalized Gold Nanoparticles. Sci. Rep. 2017, 7, 41557-41566.

49. Shen, Q.; Li, W.; Tang, S.; Hu, Y.; Nie, Z.; Huang, Y.; Yao, S. A Simple "Clickable" Biosensor for Colorimetric Detection of Copper(II) Ions Based on Unmodified Gold Nanoparticles. Biosens. Bioelectron. 2013, 41, 663-668.

50. Miao, L.-J.; Xin, J.-W.; Shen, Z.-Y.; Zhang, Y.-J.; Wang, H.-Y.; Wu, A.-G. Exploring a New Rapid Colorimetric Detection Method of $\mathrm{Cu} 2+$ With High Sensitivity and Selectivity. Sens. Actuators, B. 2013, 176, 906-912.

51. Yuan, X.; Chen, Y. Visual Determination of $\mathrm{Cu} 2+$ Through Copper-Catalysed in situ Formation of Ag Nanoparticles. Analyst. 2012, 137, 4516-4523.

52. Xu, X.; Daniel, W. L.; Mirkin, C. A. Colorimetric Cu2+ Detection Using DNAModified Gold-Nanoparticle Aggregates as Probes and Click Chemistry. Small. 2010, 6, 623-626.

53. Deng, H.-H.; Li, G.-H.; Liu, A.-L.; Chen, W.; Lin, X.-H.; Xia, X.-H. Thermally Treated Bare Gold Nanoparticles for Colorimetric Sensing of Copper Ions. Microchim. Acta. 2014,181, 911-916. 
54. Hua, C.; Zhang, W. H.; De Almeida, S. R. M.; Ciampi, S.; Gloria, D.; Liu, G.; Harper, J. B.; Gooding, J. J. A Novel Route to Copper(ii) Detection Using 'Click' Chemistry-Induced Aggregation of Gold Nanoparticles. Analyst. 2012, 137,82-86.

55. Singh, G.; Arora, A.; Rani, S.; Kalra, P.; Kumar, M. A Click-Generated Triethoxysilane Tethered Ferrocene-Chalcone-Triazole Triad for Selective and Colorimetric Detection of Cu2+ Ions. ChemistrySelect. 2017, 2, 3637-3647.

56. Yao, Z.; Yang, Y.; Chen, X.; Hu, X.; Zhang, L.; Liu, L.; Zhao, Y.; Wu, H.-C. Visual Detection of Copper(II) Ions Based on an Anionic Polythiophene Derivative Using Click Chemistry. Anal. Chem. 2013, 85, 5650-5653.

57. Mehta, V. N.; Kumar, M. A.; Kailasa, S. K. Colorimetric Detection of Copper in Water Samples Using Dopamine Dithiocarbamate-Functionalized $\mathrm{Au}$ Nanoparticles. Ind. Eng. Chem. Res. 2013, 52, 4414-4420.

58. Wang, X.; Chen, L.; Chen, L. Colorimetric Determination of Copper Ions Based on the Catalytic Leaching of Silver from the Shell of Silver-Coated Gold Nanorods. Microchim. Acta. 2014, 181, 105-110.

59. Ghodake, G. S.; Shinde, S. K.; Saratale, R. G.; Kadam, A. A.; Saratale, G. D.; Syed, A.; Ameen, F.; Kim, D.-Y. Colorimetric Detection of $\mathrm{Cu} 2+$ Based on the Formation of Peptide-Copper Complexes on Silver Nanoparticle Surfaces. Beilstein J. Nanotechnol. 2018, 9, 1414-1422.

60. Hasegawa, K.; Ono, T.; Noguchi, T. Vibrational Spectra and Ab Initio DFT Calculations of 4-Methylimidazole and Its Different Protonation Forms: Infrared and Raman Markers of the Protonation State of a Histidine Side Chain. J. Phys. Chem. B. 2000, 104, 4253-4265.

61. Costas, C.; López-Puente, V.; Bodelón, G.; González-Bello, C.; Pérez-Juste, J.; Pastoriza-Santos, I.; Liz-Marzán, L. M. Using Surface Enhanced Raman Scattering to Analyze the Interactions of Protein Receptors with Bacterial Quorum Sensing Modulators. ACS Nano. 2015, 9, 5567-5576.

62. Malek, K.; Królikowska, A.; Bukowska, J. pH and Substrate Effect on Adsorption of Peptides Containing Z and E Dehydrophenylalanine. Surface-Enhanced Raman Spectroscopy Studies on Ag Nanocolloids and Electrodes. J. Phys. Chem. B. 2014, $118,4025-4036$.

63. Feng, S.; Huang, S.; Lin, D.; Chen, G.; Xu, Y.; Li, Y.; Huang, Z.; Pan, J.; Chen, R.; Zeng, H. Surface-Enhanced Raman Spectroscopy of Saliva Proteins for the 
Noninvasive Differentiation of Benign and Malignant Breast Tumors. Int. J. Nanomed. 2015, 10, 537-547.

64. Gagoś, M.; Czernel, G.; Kaminski, D. M.; Kostro, K. Spectroscopic Studies of Amphotericin B-Cu ${ }^{2+}$ Complexes. BioMetals. 2011, 24, 915-922.

65. Szekeres, G. P.; Kneipp, J. SERS Probing of Proteins in Gold Nanoparticle Agglomerates. Front. Chem. 2019, 7, 30-30.

66. Tian, F.; Bonnier, F.; Casey, A.; Shanahan, A. E.; Byrne, H. J. Surface Enhanced Raman Scattering with Gold Nanoparticles: Effect of Particle Shape. Anal. Methods. 2014, 6, 9116-9123.

67. Accardo, A.; Shalabaeva, V.; Cotte, M.; Burghammer, M.; Krahne, R.; Riekel, C.; Dante, S. Amyloid $\beta$ Peptide Conformational Changes in the Presence of a Lipid Membrane System. Langmuir. 2014, 30, 3191-3198.

68. Colaianni, S. E. M.; Nielsen, O. F. Low-Frequency Raman Spectroscopy. J. Mol. Struct. 1995, 347, 267-283.

69. Datta, S.; Mahapatra, A. S.; Sett, P.; Ghosh, M.; Mallick, P. K.; Chakrabarti, P. K. Magnetic Behavior and Raman Spectroscopy of the Composite System of CuCl2-2H2O-C12H9NO. J.Sci.: Adv. Mat. and Devices. 2018, 3, 113-121.

70. Niveditha, C. V.; Fatima, M. J. J.; Sindhu, S. Comprehensive Interfacial Study of Potentio-Dynamically Synthesized Copper Oxide Thin Films for Photoelectrochemical Applications. J. Electrochem. Soc. 2016, 163, H426-H433.

71. Shao, N.; Jin, J. Y.; Cheung, S. M.; Yang, R. H.; Chan, W. H.; Mo, T. A SpiropyranBased Ensemble for Visual Recognition and Quantification of Cysteine and Homocysteine at Physiological Levels. Angew. Chem. Int. Ed. Engl. 2006, 45, 4944-4948. 